Article

\title{
Ascorbic Acid Rejection Characteristics of Modified Platinum Electrodes: A Shelf Life Investigation
}

\author{
Andrea M. Wynne and Niall J. Finnerty * \\ Sensors Development Unit and Neurochemistry Research Unit, BioAnalytics Laboratory, \\ Department of Chemistry, Maynooth University, Co. Kildare, Ireland; \\ E-Mail: andrea.m.wynne@gmail.com
}

* Author to whom correspondence should be addressed; E-Mail: niall.finnerty@nuim.ie; Tel.: +353-01-708-6477.

Academic Editor: Igor Medintz

Received: 22 December 2014 / Accepted: 25 March 2015 / Published: 8 April 2015

\begin{abstract}
Ascorbic acid (AA) is the principle interferent present in brain extracellular fluid that can inhibit the ability of electrochemical sensors to selectively detect a particular analyte of interest. Considerable efforts have been made in recent times to develop highly selective membrane coatings to counteract the drawbacks associated with AA interference during in vivo monitoring. The primary objective of the work described within was to investigate the long term effect of storing such selective membranes, i.e., Nafion ${ }^{\circledR}$ and Poly-o-phenylenediamine (PPD) under different conditions and how exposing them to repeated calibration protocols compromises the membranes ability to reject AA. Four different modified platinum (Pt) electrodes, Pt-PPD, Pt-Nafion ${ }^{\circledR}(5 / 2)$, Pt-Nafion ${ }^{\circledR}$ (1/2)-PPD, and Pt-Nafion ${ }^{\circledR}(2 / 1)-\mathrm{PPD}$, stored at $4{ }^{\circ} \mathrm{C}$ demonstrated deterioration of the polymers integrity when exposed to repeated calibrations. On the contrary, exposing the same four electrode types to single calibrations confirmed excellent retention of AA rejection characteristics. Pt-PPD electrodes were then exposed to varying storage conditions and calibrated against AA on day 1, day 56 and day 168. Storing the Pt-PPD electrodes at $4{ }^{\circ} \mathrm{C} / \mathrm{N}_{2}$ saturated glass container demonstrated retention of AA rejection characteristics after day 168. These results have clearly elucidated the optimum storage conditions for Pt-Nafion ${ }^{\circledR}$ and Pt-PPD modified electrodes.
\end{abstract}

Keywords: Ascorbic acid; Nafion ${ }^{\circledR}$; Poly- $o$-phenylenediamine; membrane integrity; storage 


\section{Introduction}

The mammalian brain has a large number of possible interfering species present at relatively high concentrations, (e.g., ascorbic acid (AA), uric acid (UA), and neurotransmitters including dopamine (DA) and serotonin (5-HT)). Due to its high abundance in brain extracellular fluid, AA is the principle electroactive interferent that can inhibit an electrochemical sensor's ability to selectively detect a particular analyte of interest. Possessing an $\mathrm{E}_{1 / 2}$ between -100 to $+400 \mathrm{mV} v \mathrm{~s}$. SCE, it is readily oxidised at platinum $(\mathrm{Pt})$ electrodes through a $2 \mathrm{e}^{-}$process that results in the production of L-dehydroascorbic acid [1]. Miele and Fillenz approximated an extracellular ascorbate concentration of $c a .500 \mu \mathrm{M}$ [2] which exists in anionic form at physiological $\mathrm{pH}$ and has diverse functions ranging from anti-oxidant to neuromodulator. Considerable efforts have been made in recent times to develop highly selective membrane coatings to counteract the drawbacks associated with AA interference during in vivo monitoring.

Routinely, Pt surfaces have been modified by a number of different methods including recast perfluorosulfonated ionmers and electropolymerised films. The perfluorinated ion exchange polymer Nafion ${ }^{\circledR}$, has been widely utilised as a permeable membrane in electrochemical sensor design demonstrating excellent permselective characteristics against anionic species including AA [3-6]. However, when dip adsorbed on Pt surfaces, Nafion ${ }^{\circledR}$ demonstrates cation exchange properties due to the hydrophilic ionic clusters of sulfonic acid groups that also give rise to its anionic rejection properties. Work undertaken in our research laboratory has described a novel procedure for coating Nafion ${ }^{\circledR}$ onto Pt electrode surfaces using a thermal annealing protocol [7]. The resulting Nafion ${ }^{\circledR}$ pre-coat layer completely eliminates anionic and cationic interferents from the disk surface but facilitates the diffusion of gaseous molecules such as nitric oxide (NO) and oxygen $\left(\mathrm{O}_{2}\right)$ across [8].

Poly-o-phenylenediamine (PPD) can be integrated into the design of electrochemical sensors to function either as a conducting polymer [9] or more commonly as an insulating polymer [10,11]. Electropolymerisation of the monomer $o$-phenylenediamine (o-PD) in $\mathrm{pH} 7.4$, deposits PPD in its insulating form onto the electrode surface [12]. This insulating layer appears to provide selectivity by limiting access of larger molecules such as AA, DA, etc. to the electrodes surface. Literature states that different structures of the insulating form of PPD exist, a "ladder" like structure where the amino groups are condensed within the benzene rings adjacent to each other along the polymer chain [13] and an “open" 1.4-substituted benzenoid-quinoid structure [14]. Research undertaken by Losito and colleagues suggest that the "open" form of the polymer is the more dominant structure [15].

A number of previous reports have detailed the excellent permselective properties of electrochemical sensors that incorporate both $\mathrm{Nafion}^{\circledR}$ and PPD layers in their membrane design $[6,16,17]$. It is imperative that electrochemical sensors demonstrate efficient selectivity characteristics to enable reliable in vivo recordings to be performed. Additionally it is critical that these selectivity characteristics remain intact throughout long-term storage, allowing the researcher to manufacture and calibrate sensors on separate days to in vivo implantation. This forms the basis of the work described within. Investigations were undertaken to determine the effect of various different storage conditions on the longevity of $\mathrm{Pt}$ electrodes modified with various combinations of Nafion ${ }^{\circledR}$ and PPD layers. 


\section{Experimental Section}

\subsection{Reagents and Solutions}

The Nafion ${ }^{\circledR}$ (5 wt \% solution in a mixture of lower aliphatic alcohols and $\mathrm{H}_{2} \mathrm{O}$ ), L-ascorbic acid (AA; A.C.S. reagent) and $o$-phenylenediamine ( $o$-PD, 99+\%), sodium chloride $(\mathrm{NaCl})$, sodium hydrogen phosphate $\left(\mathrm{NaH}_{2} \mathrm{PO}_{4}\right)$ and sodium hydroxide $(\mathrm{NaOH})$ were obtained from Sigma-Aldrich Ireland Ltd. Parafilm was sourced from Lennox (Dublin, Ireland).

AA stock solutions $(0.1 \mathrm{M})$ were prepared daily by dissolving $0.176 \mathrm{~g}$ in $10 \mathrm{~mL}$ of doubly distilled deionised $\mathrm{H}_{2} \mathrm{O}$. In vitro experiments were carried out in phosphate buffer saline (PBS) solution, $\mathrm{pH} 7.4$ $\left(0.15 \mathrm{M} \mathrm{NaCl}, 0.04 \mathrm{M} \mathrm{NaH}_{2} \mathrm{PO}_{4}\right.$ and $\left.0.04 \mathrm{M} \mathrm{NaOH}\right)$, which was deaerated with $\mathrm{O}_{2}$-free $\mathrm{N}_{2}$ for $20 \mathrm{~min}$ prior to commencing electrochemical measurements.

\subsection{Sensor Manufacture}

Bare Platinum (Pt) disk electrodes were made from Teflon insulated Platinum/Iridium (Pt/Ir 90\%/10\%) wire (127 $\mu \mathrm{m}$ bare diameter, $203 \mu \mathrm{m}$ coated diameter (5T), Science Products GmbH, Hofheim, Germany) as previously described. Briefly, the electrodes were approximately $5 \mathrm{~cm}$ in length and were prepared by carefully cutting $5 \mathrm{~mm}$ of the Teflon insulation from one end of the wire. A gold electrical contact (Bilaney, UK) was soldered to this end of the wire to enable connection with the instrumentation. The other end of the wire acted as the active (disk) surface of the electrode.

$P t-P P D$ refers to the electropolymerisation of $o$-PD onto the bare Pt disk electrode which was carried out by applying a constant potential of $+700 \mathrm{mV} v s$. SCE in a $300 \mathrm{mM}$ solution made up in $\mathrm{N}_{2}$ saturated PBS. The electrodes were polymerised for $30 \mathrm{~min}$ and the electrochemical cell was kept under a $\mathrm{N}_{2}$ atmosphere as the monomer is readily oxidised in air.

Nafion $^{\circledR}(5 / 2)$ refers to a previously described sensor incorporating 5 pre-coat, 2 applications of Nafion $^{\circledR}$, annealed after each application at $210{ }^{\circ} \mathrm{C}$ which has been extensively characterised in vitro $[7,8,18]$ and in vivo $[19,20]$ for the electrochemical detection of NO.

Nafion $^{\circledR}$ (1/2)-PPD refers to a previously described sensor incorporating 1 pre-coat, 2 applications of Nafion ${ }^{\circledR}$, annealed after each application at $210{ }^{\circ} \mathrm{C}$, followed by electropolymerisation in $o$-PD for $30 \min [21]$.

Nafion $^{\circledR}(2 / 1)-P P D$ refers to a previously described sensor incorporating 2 pre-coats, 1 application of Nafion ${ }^{\circledR}$, annealed at $210{ }^{\circ} \mathrm{C}$ followed by 1 dip into $5 \%$ Nafion ${ }^{\circledR}$ solution, annealed at $210{ }^{\circ} \mathrm{C}$ and finally electropolymerised in $o$-PD for $30 \mathrm{~min}$ [21].

The previously reported pre-coat application method involves placing a fixed volume $(5 \mu \mathrm{L})$ of Nafion ${ }^{\circledR}$ on a clock glass using a syringe which is allowed to air dry at room temperature for $5 \mathrm{~min}$ (repeated up to 5 times depending on the sensor type). A fresh application of $\mathrm{Nafion}^{\circledR}$ (one or two depending on the sensor type) is placed onto the concentrated pre-coat of Nafion ${ }^{\circledR}$. The active surface of the electrode is dipped into this concentrated layer and then immediately removed and let air dry at room temperature for $2 \mathrm{~min}$. The electrodes are then placed in the oven and annealed for $5 \mathrm{~min}$ at $210{ }^{\circ} \mathrm{C}$. After the annealing process has been completed, the electrode is coated again (depending on number of pre-coats) using the same procedure i.e., placing another application of $\mathrm{Nafion}^{\circledR}$ onto the concentrated 
layer and dipped into this concentrated layer and then immediately removed and let air dry at room temperature for $2 \mathrm{~min}$.

\subsection{Storage Conditions}

Enclosed container at $4{ }^{\circ} \mathrm{C}$ : Polymer modified electrodes were stored dry in a glass cell sealed tight with a lid and parafilm.

$\mathrm{N}_{2}$ saturated $\mathrm{PBS}$ solution at $4{ }^{\circ} \mathrm{C}$ : Polymer modified electrodes were stored in a glass cell containing $10 \mathrm{mLs}$ of PBS which had been purged for $20 \mathrm{~min}$ prior to storage. The cell was sealed tight with a lid and parafilm.

$\mathrm{N}_{2}$ saturated enclosed container at $4{ }^{\circ} \mathrm{C}$ : Polymer modified electrodes were stored in a glass cell which had been purged with $\mathrm{N}_{2}$ for 20 min prior to storage. The cell was sealed tight with a lid and parafilm.

Enclosed container at $-20{ }^{\circ} \mathrm{C}$ : Polymer modified electrodes were stored dry in a glass cell sealed tight with a lid and parafilm.

\subsection{AA Calibrations}

All calibrations were performed in a standard three-electrode glass electrochemical cell which was constructed in house. A saturated calomel electrode (SCE) was used as the reference electrode and a large Pt wire served as the auxiliary electrode. All calibrations were performed at $+900 \mathrm{mV} v s$. SCE to investigate the membranes suitability for incorporation into nitric oxide sensor designs. Following each AA calibration, the sensor tips were rinsed in deionised water to remove trace amounts of adsorbed salt and were returned to their respective storage conditions. To facilitate mixing, solutions were agitated using a magnetic stirrer for approximately $5 \mathrm{~s}$ following the addition of each aliquot. The current was then measured under quiescent conditions with a $\mathrm{N}_{2}$ atmosphere maintained over the solution.

\subsection{Instrumentation and Software}

Constant potential amperometry (CPA) was performed as previously described. Briefly, all electrochemical experiments used a low-noise four channel biostat (ACM instruments; Cumbria, UK). Data acquisition was carried out with a logiQ M760TG notebook with an Intel dual core processor, an eight channel powerlab ${ }^{\circledR}$ 8/30 from (ADInstruments Ltd; Oxford, UK) and LabChart for Windows (v 6.1) software (ADInstruments Ltd., Oxford, UK). Scanning Electron Microscopy was performed on a Hitachi S-3200N.

\section{Results and Discussion}

\subsection{Shelf-Life Studies-Effect of Repeated AA Calibrations}

PPD modified Pt electrodes are extensively utilised to improve selectivity of the polymer layer of both electrochemical sensors [6,17,22-24] and biosensors [11,25-28] since extracellular concentrations of certain metabolites are considered low in relation to the excessive concentration of AA. Therefore it is imperative that the integrity of the polymer is retained following implantation. Moreover, the ability 
of the polymer to selectively detect the analyte of interest must be verified prior to implant. The investigation of a polymers shelf-life is therefore a prerequisite prior to its utilisation in physiological determinations since sensors are manufactured and stored prior to deployment. Figure 1 illustrates the effect of storing Pt-PPD electrodes in an enclosed glass container at $4{ }^{\circ} \mathrm{C}$ over the course of 56 days. The electrodes were calibrated on day 1, 3, 7, 14, 28 and 56 with the maximum current recorded at $1000 \mu \mathrm{M}$ AA. In detail, day $3(147 \pm 10 \mathrm{pA}, n=4)$, day $7(150 \pm 53 \mathrm{pA}, n=4)$ and day 14 $(590 \pm 224 \mathrm{pA}, n=4)$ demonstrated no significant difference $(p>0.05)$ from day $1(138 \pm 19 \mathrm{pA}$, $n=4)$. However, day $28(1847 \pm 684 \mathrm{pA}, n=4)$ and day $56(2707 \pm 1031 \mathrm{pA}, n=4)$ revealed significant differences $(p<0.05)$.

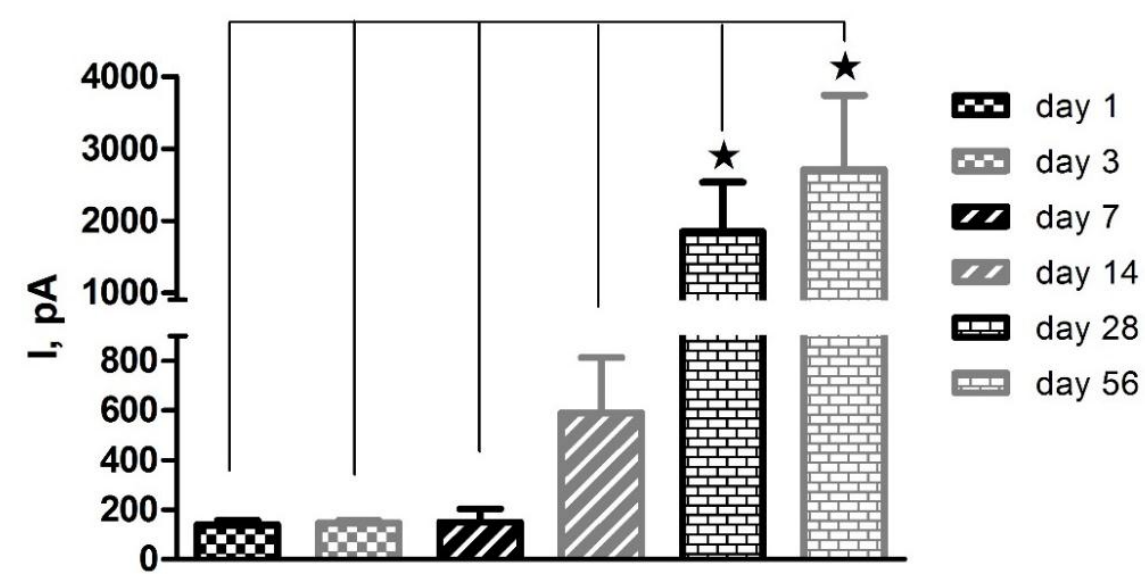

Figure 1. Comparison of the effects of repeated calibrations on the shelf life of platinum-poly-o-phenylenediamine (Pt-PPD) electrodes. Data represents maximum current recorded at $1000 \mu \mathrm{M}$ ascorbic acid (AA) for Pt-PPD $(n=4)$ electrodes.

The current-concentration profile in Figure 2 highlights the ability of the PPD polymer to facilitate the transport of AA at the lower concentrations. This feature diminishes with subsequent injections as the polymer pore size self-blocks the diffusion of incoming AA due to the entrapment of AA and its oxidised metabolite dehydroascorbic acid (DHA) within the PPD polymer matrix. This has been reported previously $[29,30]$ and is characteristic of PPD polymers. It is interesting to note that linearity returns after day 56 in contrast to the self-blocking effect observed on day 1 . The levels detected are still considerably lower than at a bare Pt electrode $\left(37,000 \pm 1000 \mathrm{pA} \mathrm{mM}^{-1}, n=14\right)$ but are considered too high for physiological applications. The augmented linear response after day 56 theorises that the overall integrity of the PPD polymer remains intact, however, the polymer pore size increases following storage and repeated calibrations. A plausible explanation for this can be attributed to the effect of repeated entrapment of the AA molecule within the pores of the PPD matrix over successive calibrations. Constant exposure to AA results in a detrimental effect due to damage inflicted on the PPD pores upon removal of the interferent from the polymer membrane following cessation of the calibration and re-storage. This removes the self-blocking effect observed on day 1 by facilitating the diffusion of larger concentrations of AA to the electrodes surface and removing the possibility of AA/DHA entrapment within the matrix. A similar phenomenon was reported by Geise and co-workers utilising reticulated vitreous carbon coated with PPD. After 60 days the response of a poly (1,2-DAB) covered electrode to repeated calibrations of $1 \mathrm{mM}$ acetaminophen was over $15 \%$ of the original bare electrode response [31]. 


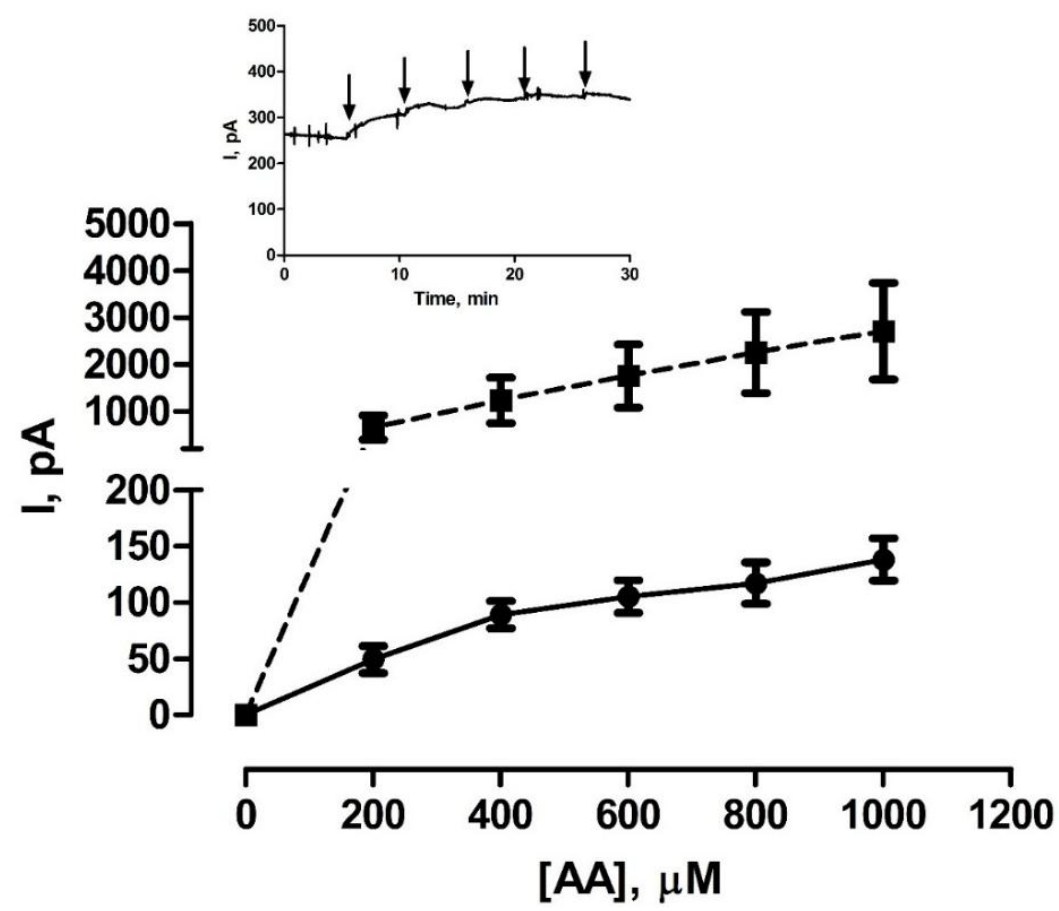

Figure 2. A current-concentration profile for $0-1000 \mu \mathrm{M}$ AA on Pt-PPD electrodes on day 1 ( $n=4$, solid line) $v s$. day $56\left(4{ }^{\circ} \mathrm{C}\right.$ storage, $n=4$, dashed line $)$ at $+900 \mathrm{mV} v s$. saturated calomel electrode (SCE). Electrodes calibrated on day 1, 3, 7, 14, 28, and 56. (Inset) Typical raw data trace. Arrows indicate injection of AA aliquot.

Table 1 details the permselective characteristics of the four different types of Pt modified electrodes utilised throughout this study. All electrode types were exposed to the same storage conditions and calibration parameters. Pt-Nafion ${ }^{\circledR}(5 / 2)$ sensors incorporate an annealed form of the perfluorinated sulfonic acid ionomer on the electrode surface which has demonstrated excellent rejection characteristics previously [8]. In the past Nafion ${ }^{\circledR}$ has been employed in electrochemical sensor design for its dual ability as both a cation exchange polymer [32-35] and an anionic rejection layer [4-6]. However, the described Nafion ${ }^{\circledR}$ pre-coat method displays both anionic and cationic rejection characteristics while facilitating the diffusion of gaseous molecules such as $\mathrm{NO}$ and $\mathrm{O}_{2}$ to the electrode surface. The extremely selective nature of this film can be attributed to the annealing procedure which reduces the permeability of the film by increasing the crystallinity of the film [36,37]. Similar to the Pt-PPD electrode, the maximum current recorded at $1000 \mu \mathrm{M}$ AA on day $3(260 \pm 211 \mathrm{pA}, n=4)$, day $7(592 \pm 328 \mathrm{pA}$, $n=4)$, day $14(1254 \pm 902 \mathrm{pA}, n=4)$ and day $28(1598 \pm 1099 \mathrm{pA}, n=4)$ demonstrated no significant difference $(p>0.05)$ from day $1(131 \pm 29 \mathrm{pA}, n=4)$, though, day $56(2707 \pm 1031 \mathrm{pA}, n=4)$ did reveal a significant difference $(p<0.05)$. It is possible that storing the sensor over time and repeatedly exposing them to calibrations has resulted in cracking of the Nafion ${ }^{\circledR}$ membrane leading to an increased permeability to AA. This has been reported previously by Mercado et al., who demonstrated that curing Nafion $^{\circledR}$ at a high temperature reduces cracking somewhat, but does not eliminate it entirely [38]. It is worth noting that their work relates to subcutaneously implanted sensors, however, a similar phenomenon can be attributed to the work described within. The process of calibrating the sensor in electrolyte and subsequently storing the electrode compromises the integrity of the Nafion ${ }^{\circledR}$ modified surface resulting in eventual cracking of the crystalline structure. A possible explanation is the adsorption 
of salts from the electrolyte augments the permeability of the polymer to AA following frequent exposure. Mercado et al. refer to the calcification of Nafion ${ }^{\circledR}$ polymers following implantation, resulting in an increase in the membranes permeability to interferent molecules. Due to the hydrophilic sulfonic groups and the hydrophobic fluorocarbon backbone within $\mathrm{Nafion}^{\circledR}$, it is conceivable that this contributes to calcification. Therefore it is plausible that this translates to the results described within, whereby salts from the PBS electrolyte adsorb on the Nafion ${ }^{\circledR}$ surface after repeated exposure, compromising its integrity over time.

Table 1. Shelf-life data for various platinum $(\mathrm{Pt})$-modified electrodes. Electrodes calibrated on day $1,3,7,14,28$, and 56. Data represents maximum current recorded at $1000 \mu \mathrm{M}$ ascorbic acid (AA) for each electrode type $(n=4)$. “ $\star$ ” denotes level of significance against day 1. "ns" denotes no significant change.

\begin{tabular}{|c|c|c|c|c|c|c|c|c|c|c|c|c|}
\hline \multirow[b]{2}{*}{ Day } & \multicolumn{3}{|c|}{ Pt-PPD } & \multicolumn{3}{|c|}{ Pt-Nafion ${ }^{\circledR}(5 / 2)$} & \multicolumn{3}{|c|}{ Pt-Nafion $^{\circledR}(1 / 2)$-PPD } & \multicolumn{3}{|c|}{ Pt-Nafion $^{\circledR}(2 / 1)$-PPD } \\
\hline & Mean I (pA) & $S E M$ & Stats & Mean I (pA) & $S E M$ & Stats & Mean I (pA) & $S E M$ & Stats & Mean I (pA) & SEM & Stats \\
\hline 1 & 138 & 19 & & 131 & 29 & & -59 & 10 & & 2 & 10 & \\
\hline 3 & 147 & 10 & ns & 260 & 211 & $\mathrm{~ns}$ & 141 & 107 & $\mathrm{~ns}$ & 8 & 1 & $\mathrm{~ns}$ \\
\hline 7 & 150 & 53 & $\mathrm{~ns}$ & 592 & 328 & ns & 2583 & 944 & * & 473 & 156 & * \\
\hline 14 & 590 & 224 & $\mathrm{~ns}$ & 1254 & 902 & $\mathrm{~ns}$ & 2910 & 1000 & * & 1328 & 408 & * \\
\hline 28 & 1847 & 684 & * & 1598 & 1099 & ns & 3299 & 1049 & * & 2231 & 594 & $\star \star$ \\
\hline 56 & 2707 & 1031 & * & 3239 & 1175 & $\star$ & 6539 & 1504 & $\star \star$ & 4434 & 665 & 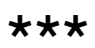 \\
\hline
\end{tabular}

Previously, a number of groups have investigated the simultaneous combination of $\mathrm{Nafion}^{\circledR}$ and PPD on carbon fiber electrodes in the expectation of improving sensor performance $[6,16,17,39]$. Two variations of this polymer combination were investigated and the results are presented in Table 1. Briefly, for Pt-Nafion ${ }^{\circledR}(1 / 2)-P P D$ modified sensors the maximum current recorded at $1000 \mu \mathrm{M}$ AA on day $3(141 \pm 107 \mathrm{pA}, n=4)$ demonstrated no significant difference $(p>0.05)$ from day $1(-59 \pm 10 \mathrm{pA}$, $n=4)$. In contrast, the remaining day $7(2583 \pm 944 \mathrm{pA}, n=4)$, day $14(2910 \pm 1000 \mathrm{pA}, n=4)$ and day $28(3299 \pm 1049 \mathrm{pA}, n=4)$ did reveal a significant difference $(p<0.05)$, as did day 56 $(6539 \pm 1504 \mathrm{pA}, n=4, p<0.01)$. The negative current below baseline levels on day 1 can be attributed to zero response from AA aliquots and the background current drifting below the previously recorded baseline value over the time scale of the calibration. Similarly, for Pt-Nafion ${ }^{\circledR}(2 / 1)$-PPD modified sensors the maximum current recorded at $1000 \mu \mathrm{M}$ AA on day $3(8 \pm 1 \mathrm{pA}, n=4)$ demonstrated no significant difference $(p>0.05)$ from day $1(2 \pm 10 \mathrm{pA}, n=4)$. However, day $7(473 \pm 156 \mathrm{pA}, n=4$, $p<0.05)$, day $14(2910 \pm 1000 \mathrm{pA}, n=4, p<0.05)$, day $28(2231 \pm 594 \mathrm{pA}, n=4, p<0.01))$ and day 56 (4434 $\pm 665 \mathrm{pA}, n=4, p<0.0001)$ all resulted in significant differences from day 1. These investigations suggest that modifying Pt electrodes with a combination of Nafion ${ }^{\circledR} / \mathrm{PPD}$ yielded a less stable membrane which may be due in part to the process of electropolymerising PPD onto a non-uniform Nafion ${ }^{\circledR}$ pre-coat surface as opposed to a bare Pt surface. Friedemann et al. reported that Nafion ${ }^{\circledR}$ must be applied prior to the electropolymerisation of PPD because if applied in the reverse order, the selectivity profile is greatly diminished. It was suggested that the alcohols in which Nafion ${ }^{\circledR}$ is dissolved was removing the PPD layer and compromising functionality [6]. It is apparent from Figure 3 that the annealed Nafion ${ }^{\circledR}$ pre-coat layer on both designs is disproportionate which theoretically, may result in an inefficient subsequent PPD electropolymerisation process. This is in stark contrast to 
the PPD layer grown on bare Pt which can be controlled more efficiently due to the self-limiting characteristic associated with the polymer during the electropolymerisation process. A number of groups report the thickness of PPD polymers to be between 10 and $30 \mathrm{~nm}[12,40,41]$. Similarly, Nafion ${ }^{\circledR}$ has been electrodeposited onto carbon electrode surfaces as a method of incorporating a uniform reproducible layer to ameliorate issues associated with dip coating and annealing [3,32,42]. However, despite an improvement in Nafion ${ }^{\circledR}$ membrane uniformity and thickness, selectivity against cationic species including the catecholamines was insufficient.
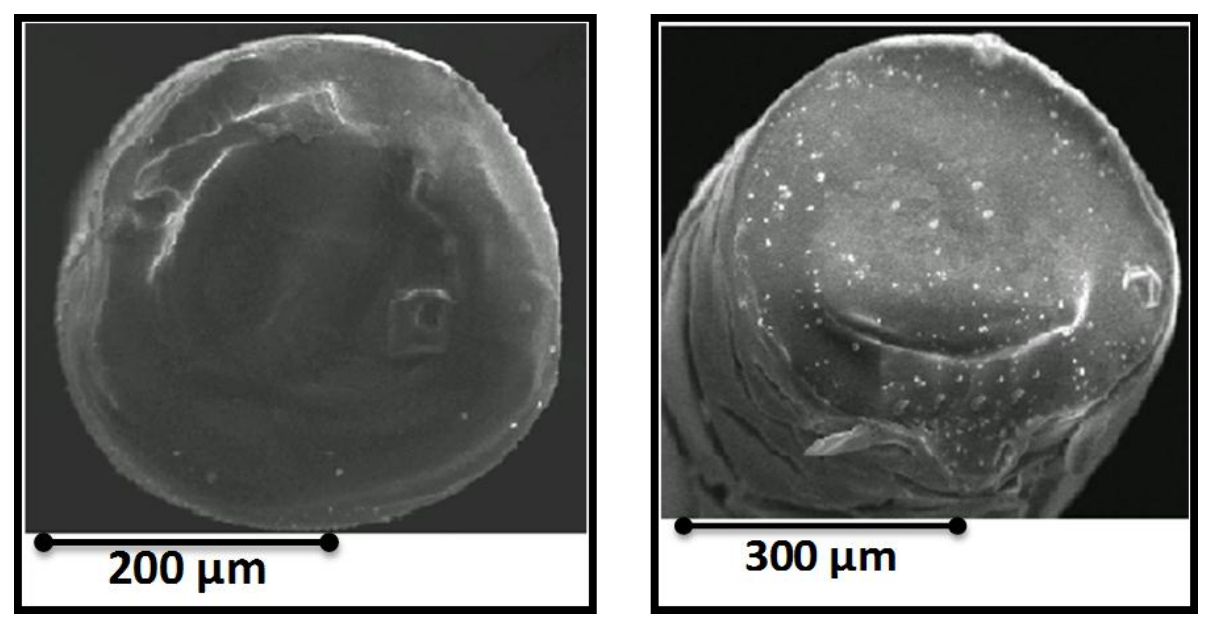

Figure 3. Scanning Electron Microscopy (SEM) of (Left) Pt-Nafion ${ }^{\circledR}(1 / 2) \mathrm{PPD}$ modified electrode, $200 \mu \mathrm{m}$ dimensional bar (Right) Pt-Nafion ${ }^{\circledR}(2 / 1)$ PPD modified sensor, $300 \mu \mathrm{m}$ dimensional bar.

We hypothesise that this weakened PPD layer deteriorates more rapidly following repeated exposure to calibrations and storage, more than likely due to a compromised PPD electropolymerisation process. The exposed pre-coats of Nafion ${ }^{\circledR}$ will undergo cracking as described earlier resulting in larger AA currents detected over time. Based on these findings an alternative method of calibration was investigated which better represents shelf-life studies and removes the discrepancies observed with repeated exposures.

\subsection{Shelf-Life Studies-Effect of Single AA Calibration}

To confirm the detrimental impact of repeated calibrations on the integrity of the respective polymer modified electrodes, it was decided to investigate the effect of a single AA calibration after 56 days storage. Sensors were initially calibrated on day 1 as described previously and stored in an enclosed container at $4{ }^{\circ} \mathrm{C}$ for 56 days. A second calibration was thus performed on day 56. Figure 4 illustrates current concentration profiles for $0-1000 \mu \mathrm{M}$ AA on Pt-PPD electrodes on day 1 and day 56 respectively. There is essentially no change in AA detection with the maximum current recorded at $1000 \mu \mathrm{M} \mathrm{AA}$ on day $56(24 \pm 2 \mathrm{pA}, n=4)$ demonstrating no significant difference $(p>0.05)$ from day 1 $(19 \pm 4 \mathrm{pA}, n=4)$. 


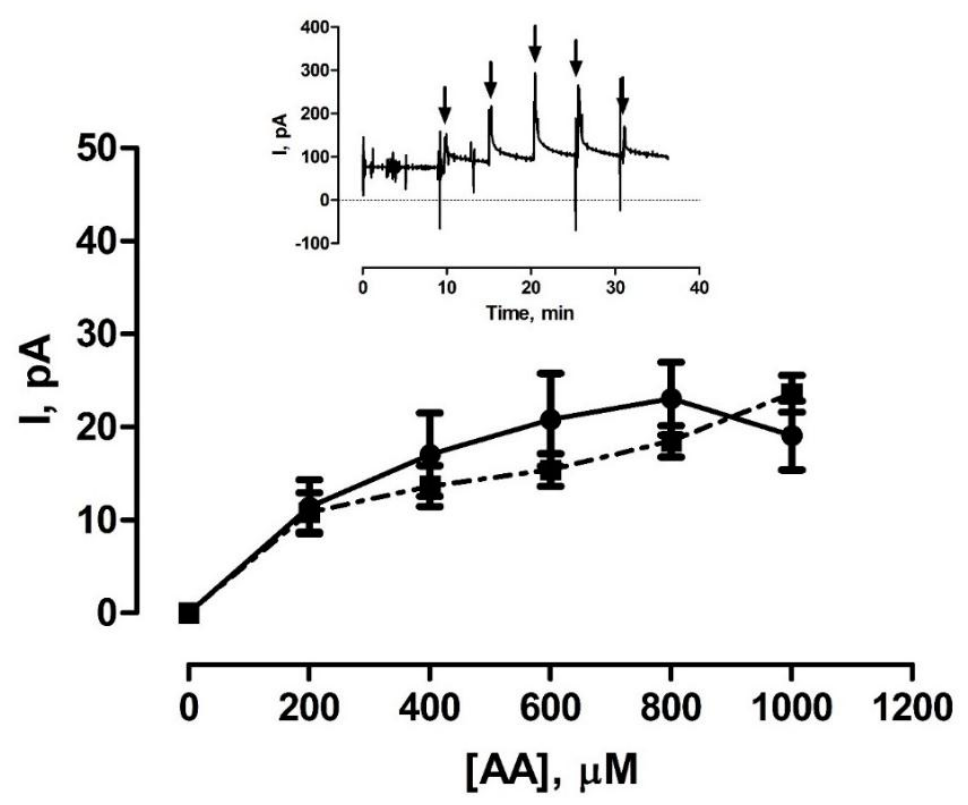

Figure 4. A current-concentration profile for $0-1000 \mu \mathrm{M}$ AA on Pt-PPD electrodes on day $1(n=4$, solid line $) v s$. day $56\left(4{ }^{\circ} \mathrm{C}\right.$ storage, $n=4$, dashed line $)$ at $+900 \mathrm{mV} v s$. SCE. Electrodes calibrated on day 1 and 56. (Inset) Typical raw data trace. Arrows indicate injection of AA aliquot.

Similar findings were observed for the remaining sensor types which are illustrated in Figure 5. In detail, the maximum current recorded at $1000 \mu \mathrm{M}$ AA on day 56 for Pt-Nafion ${ }^{\circledR}(5 / 2)$ sensors $(-5 \pm 1 \mathrm{pA}, n=4)$ was not significantly different $(p>0.05)$ from day $1(-2 \pm 1 \mathrm{pA}, n=4)$. As alluded to earlier the negative current below baseline levels can be attributed to the background current falling below the previously recorded baseline value over the course of the calibration. Pt-Nafion ${ }^{\circledR}(1 / 2)$-PPD and Pt-Nafion ${ }^{\circledR}(2 / 1)$-PPD sensors displayed maximum AA currents of $60 \pm 30 \mathrm{pA}, n=4$ and $3 \pm 1 \mathrm{pA}$, $n=4$ respectively on day 56. These levels were not significantly different $(p>0.05)$ than those recorded on day $1(6 \pm 1 \mathrm{pA}, n=4)$ and $(1 \pm 1 \mathrm{pA}, n=4)$ respectively. Collectively these findings support the theory that repeated exposure to calibration conditions and subsequent storage compromises the integrity of the various polymers. This theory is further reinforced by findings from a third calibration performed after 168 days on the respective sensors incorporating Nafion ${ }^{\circledR}$. There was still negligible detection of AA at Pt-Nafion ${ }^{\circledR}(5 / 2)$ sensors $(-22 \pm 3$ pA, $n=4)$, Pt-Nafion ${ }^{\circledR}(1 / 2)$-PPD $(117 \pm 40 \mathrm{pA}, n=4)$ and Pt-Nafion ${ }^{\circledR}(2 / 1)-P P D(-32 \pm 7 \mathrm{pA}, n=4)$ after this extended period. There is substantial improvement in the AA rejection characteristics of all sensor types when compared against the repeated exposure detailed in Table 1 . These findings postulate that the longevity of these polymer modified electrodes is in fact dictated by the frequency of exposure to calibration protocols and the interferent molecule as opposed to the duration left on the shelf. This bodes well for the manufacture and storage of these sensors for in vivo investigations and eventual commercialisation. 


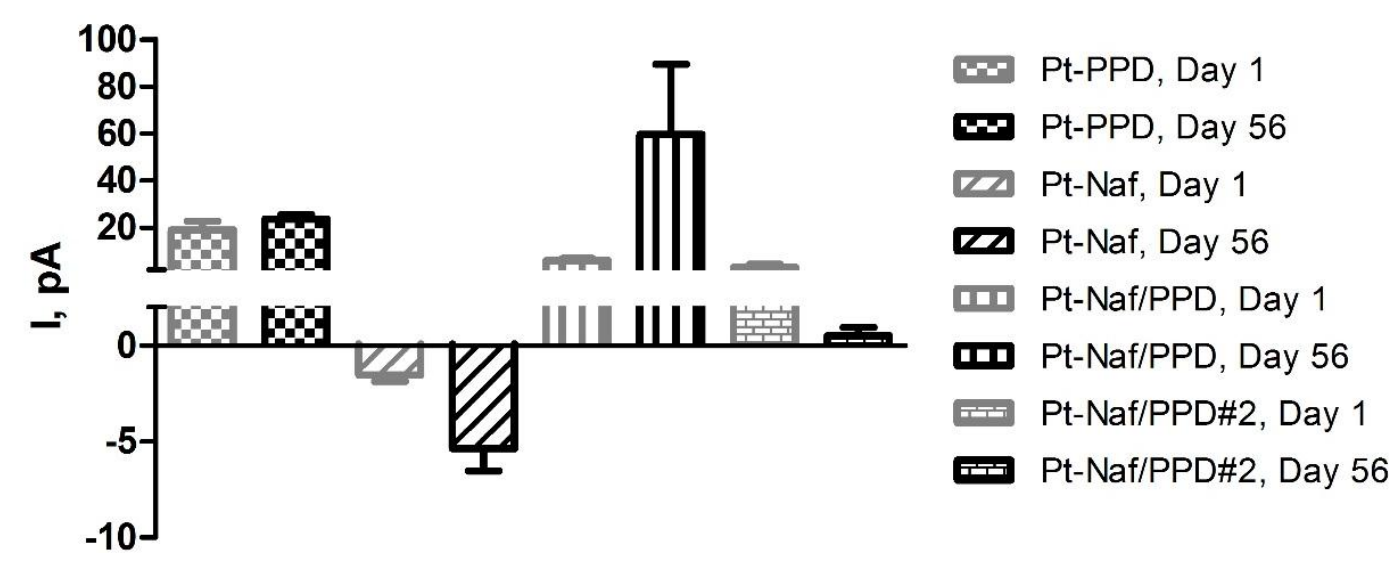

Figure 5. Effect of a single calibration on the shelf life of various Pt electrodes (Pt-PPD, Pt-Nafion ${ }^{\circledR}(5 / 2), \quad$ Pt-Nafion ${ }^{\circledR}(1 / 2)-P P D, \quad$ and $\quad$ Pt-Nafion ${ }^{\circledR}(2 / 1)-P P D$. Data represents maximum current recorded at $1000 \mu \mathrm{M}$ AA for each electrode type $(n=4)$.

\subsection{Effect of Various Storage Conditions on Shelf Life of Pt-PPD Electrodes}

The work described thus far involved storing Pt-PPD sensors at $4{ }^{\circ} \mathrm{C}$ in an enclosed glass cell container. A popular protocol employed by a number of different research groups involves storing sensors in PBS at $4{ }^{\circ} \mathrm{C}[29,43,44]$, however, based on findings from this study it appears that these conditions may deteriorate the polymers. To investigate this, Pt-PPD sensors were exposed to a number of different storage conditions and the results are detailed in Table 2.

Table 2. Shelf-life data for Pt-PPD electrodes exposed to various storage conditions $\left(4{ }^{\circ} \mathrm{C}, 4{ }^{\circ} \mathrm{C} / \mathrm{N}_{2}\right.$ saturated PBS, $4{ }^{\circ} \mathrm{C} / \mathrm{N}_{2}$ saturated, and $-20^{\circ} \mathrm{C}$ ). Electrodes calibrated on day 1 , 56 , and 168. Data represents maximum current recorded at $1000 \mu \mathrm{M}$ AA for each electrode $(n=4)$. “ $\star$ " denotes level of significance against day 1. "ns" denotes no significant change.

\begin{tabular}{|c|c|c|c|c|c|c|c|c|c|c|c|c|}
\hline \multirow[b]{2}{*}{ Day } & \multicolumn{3}{|c|}{$4^{\circ} \mathrm{C}$} & \multicolumn{3}{|c|}{$4^{\circ} \mathrm{C} / \mathrm{N}_{2}$ Saturated PBS } & \multicolumn{3}{|c|}{$4^{\circ} \mathrm{C} / \mathrm{N}_{2}$ Saturated } & \multicolumn{3}{|c|}{$-20^{\circ} \mathrm{C}$} \\
\hline & $\operatorname{Mean} I(p A)$ & SEM & Stats & Mean I (pA) & SEM & Stats & Mean I (pA) & SEM & Stats & Mean I (pA) & SEM & Stats \\
\hline 1 & 19 & 4 & & 18 & 7 & & 251 & 27 & & 139 & 23 & \\
\hline 56 & 24 & 2 & $\mathrm{~ns}$ & 1123 & 121 & $\star \star \star *$ & 295 & 105 & ns & 804 & 302 & * \\
\hline 168 & 3490 & 1276 & * & 4057 & 122 & $\star \star \star$ & 222 & 131 & $\mathrm{~ns}$ & 1706 & 615 & * \\
\hline
\end{tabular}

As discussed previously for Pt-PPD electrodes stored in an enclosed container at $4{ }^{\circ} \mathrm{C}$, there is essentially no change in the AA levels detected with the maximum current recorded at $1000 \mu \mathrm{M}$ AA on day $56(24 \pm 2 \mathrm{pA}, n=4)$ demonstrating no significant difference $(p>0.05)$ from day $1(19 \pm 4 \mathrm{pA}$, $n=4)$. However, extending the investigations out to 168 days $(3490 \pm 1276 \mathrm{pA}, n=4)$ resulted in a significant difference $(p<0.05)$ being observed. This considerable increase in AA detection suggests that re-storing the PPD modified electrodes subsequent to the previous calibrations has greatly affected the polymer layer. A possible explanation might be due to drying of the layer, producing a brittle composition which gradually weakens over time.

To examine if storing the Pt-PPD electrodes dry had an adverse effect on polymer integrity, a separate set were stored in $\mathrm{N}_{2}$ saturated PBS at $4{ }^{\circ} \mathrm{C}$ over the same time course. The maximum currents recorded at $1000 \mu \mathrm{M}$ AA on day $168(4057 \pm 122 \mathrm{pA}, n=4)$ and day $56(1123 \pm 121 \mathrm{pA}, n=4)$ were significantly 
different $(p<0.0001)$ from day $1(18 \pm 7 \mathrm{pA}, n=4)$. This clearly highlights the fact that storing the PPD modified electrodes in solution greatly compromises the interference rejection characteristics and shortens the shelf-life dramatically. This is supported by work undertaken by Gyurcsanyi et al., whereby they evaluated the effect of different storage conditions on the stability of the PPD size exclusion layers under dry and wet conditions. They reported that none of the dry stored electrodes showed measurable current in the presence of ascorbic acid and acetaminophen, however, these studies were only conducted over a 15 day period [45]. Further to this, Sasso and colleagues investigated the effect of storing PPD coated electrodes in $0.1 \mathrm{M}$, pH 6.5 phosphate buffer at $4{ }^{\circ} \mathrm{C}$. The polymer film degradation was followed for 62 days and the interference current increased linearly at a rate of $4.26 \times 10^{-2} \mu \mathrm{A} /$ day [46].

Based on this rationale, it was decided to investigate the effect of $\mathrm{N}_{2}$ saturating the glass container for 20 min prior to enclosing the electrodes and storing them at $4{ }^{\circ} \mathrm{C}$. There was a dramatic improvement in the longevity of the Pt-PPD electrodes stored at these conditions. Maximum currents recorded at $1000 \mu \mathrm{M}$ AA on day $168(222 \pm 131 \mathrm{pA}, n=4)$ and day $56(295 \pm 105 \mathrm{pA}, n=4)$ were not significantly different $(p>0.05)$ from day $1(251 \pm 27 \mathrm{pA}, n=4)$. This significant improvement in shelf-life postulates a contribution of $\mathrm{O}_{2}$ to the gradual deterioration of the PPD polymer layer associated with previous storage conditions. Findings from our laboratory strongly support this theory and the PPD electropolymerisation protocol routinely utilised stringently ensures that $\mathrm{O}_{2}$ interference is maintained at zero. We hypothesise that a tightly regulated $\mathrm{O}_{2}$ free polymerisation will ensure smaller pore sizes scattered throughout the PPD layer guaranteeing lower levels of AA diffuse across to the electrode surface over extended periods.

Finally, a set of Pt-PPD electrodes were stored at $-20{ }^{\circ} \mathrm{C}$ to determine the effect of freezing on the polymer matrix. The maximum currents recorded at $1000 \mu \mathrm{M}$ AA on day $168(1706 \pm 615 \mathrm{pA}, n=4)$ and day $56(804 \pm 302 \mathrm{pA}, n=4)$ were significantly different $(p<0.05)$ from day $1(139 \pm 23 \mathrm{pA}$, $n=4)$. It is obvious from these results that storing the electrodes at such a low temperature has had a detrimental effect on the rejection characteristics of the polymer layer and should be avoided.

\section{Conclusions}

The body of work described within clearly demonstrates that exposing various polymer modified electrodes to repeated AA calibration protocols compromises their shelf-life over a 56 day period. Contrary to this, a single AA calibration performed post manufacture prior to storage, demonstrated no significant difference from a second calibration performed 56 days later. Further, a number of different storage conditions for Pt-PPD electrodes were investigated over an extended storage period. It was clearly evident that storing the electrodes dry, in a $\mathrm{N}_{2}$ saturated glass container at $4{ }^{\circ} \mathrm{C}$ ensured the polymers integrity was retained after 168 days. These findings are extremely positive and highlight the ability to manufacture and store various polymer modified electrodes suitable for in vivo deployment at a later date. Such insight is invaluable if considering commercialising the sensor technology for industrial deployment. Elucidating the optimum conditions for storage and transport are a prerequisite for a successful company. 


\section{Acknowledgments}

We gratefully acknowledge financial support from South Dublin County Council, the Centre of Applied Science for Health which is funded by the Higher Education Authority under the Programme for Research in Third Level Institutions (PRTLI) Cycle 4, Blue Box Sensors Limited, Enterprise Ireland (EI/IV/2010/3110) and EI/IV/2012/3272) and the European Regional Development Fund (ERDF). We thank Prof. John P. Lowry for helpful discussions.

\section{Author Contributions}

Andrea Wynne carried out all of the experiments detailed within this article. Niall Finnerty compiled the paper based on this data.

\section{Conflicts of Interest}

The authors declare no conflict of interest.

\section{References}

1. Lowry, J.P.; O’Neill, R.D. Neuroanalytical chemistry in vivo using electrochemical sensors. Encycl. Sens. 2006, 10, 1-23.

2. Miele, M.; Fillenz, M. In vivo determination of extracellular brain ascorbate. J. Neurosci. Methods 1996, 70, 15-19.

3. Alpat, S.; Alpat, S.K.; Telefoncu, A. A sensitive determination of dopamine in the presence of ascorbic acid using a Nafion-coated clinoptilolite-modified carbon paste electrode. Anal. Bioanal. Chem. 2005, 383, 695-700.

4. Cass, W.A.; Gerhardt, G.A.; Mayfield, R.D.; Curella, P.; Zahniser, N.R. Differences in dopamine clearance and diffusion in rat striatum and nucleus accumbens following systemic cocaine adminstration. J. Neurochem. 1992, 59, 259-266.

5. Friedemann, M.N.; Gerhardt, G.A. Regional effects of aging on dopaminergic function in the fischer-344 rat. Neurobiol. Aging 1992, 13, 325-332.

6. Friedemann, M.N.; Robinson, S.W.; Gerhardt, G.A. O-phenylenediamine-modified carbon fiber electrodes for the detection of nitric oxide. Anal. Chem. 1996, 68, 2621-2628.

7. Brown, F.O.; Lowry, J.P. Microelectrochemical sensors for in vivo brain analysis: An investigation of procedures for modifying pt electrodes using Nafion. Analyst 2003, 128, 700-705.

8. Brown, F.O.; Finnerty, N.J.; Lowry, J.P. Nitric oxide monitoring in brain extracellular fluid: Characterisation of Nafion ${ }^{\circledR}$-modified Pt electrodes in vitro and in vivo. Analyst 2009, 134, 2012-2020.

9. Ariffin, A.A.; O’Neill, R.D.; Yahya, M.Z.A.; Zain, Z.M. Electropolymerization of ortho-phenylenediamine and its use for detection on hydrogen peroxide and ascorbic acid by electrochemical impedance spectroscopy. Int. J. Electrochem. Sci. 2012, 7, 10154-10163.

10. Lowry, J.P.; McAteer, K.; el Atrash, S.S.; Duff, A.; O’Neill, R.D. Characterisation of glucose oxidase modified poly (phenylenediamine) coated electrodes in vitro and in vivo: Homogenous interference by ascorbic acid in hydrogen peroxide detection. Anal. Chem. 1994, 66, 1754-1761. 
11. McMahon, C.P.; Rocchitta, G.; Kirwan, S.M.; Killoran, S.J.; Serra, P.A.; Lowry, J.P.; O’Neill, R.D. Oxygen tolerance of an implantable polymer/enzyme composite glutamate biosensor displaying polycation-enhanced substrate sensitivity. Biosens. Bioelectron. 2007, 22, 1466-1473.

12. Malitesta, C.; Palmisano, F.; Torsi, L.; Zambonin, P.G. Glucose fast-response amperometric sensor based on glucose-oxidase immobilised in an electropolymerized poly(ortho-phenylenediamine) film. Anal. Chem. 1990, 62, 2735-2740.

13. Chiba, K.; Ohsaka, T.; Ohnuki, Y.; Oyama, N. Electrochemical preparation of a ladder polymer containing phenazine rings. J. Electroanal. Chem. 1987, 219, 117-124.

14. Yano, J. Electrochemical and structural studies on soluble and conducting polymer from o-phenylenediamine. J. Polym. Sci. Part A Polym. Chem. 1995, 33, 2435-2441.

15. Losito, I.; Palmisano, F.; Zambonin, P.G. O-phenylenediamine electropolymerization by cyclic voltammetry combined with electrospray ionization-ion trap mass spectrometry. Anal. Chem. 2003, 75, 4988-4995.

16. Ferreira, N.R.; Ledo, A.; Frade, J.G.; Gerhardt, G.A.; Laranjinha, J.; Barbosa, R.M. Electrochemical measurement of endogenously produced nitric oxide in brain slices using Nafion/o-phenylenediamine modified carbon fiber microelectrodes. Anal. Chim. Acta 2005, 535, $1-7$.

17. Park, J.K.; Tran, P.H.; Chao, J.K.; Ghodadra, R.; Rangarajan, R.; Thakor, N.V. In vivo nitric oxide sensor using non-conducting polymer-modified carbon fiber. Biosens. Bioelectron. 1998, 13, 1187-1195.

18. Brown, F.O.; Finnerty, N.J.; Bolger, F.B.; Millar, J.; Lowry, J.P. Calibration of no sensors for in vivo voltammetry: Laboratory synthesis of NO and the use of UV-visible spectroscopy for determining stock concentrations. Anal. Bioanal. Chem. 2005, 381, 964-971.

19. Finnerty, N.J.; O’Riordan, S.L.; Brown, F.O.; Serra, P.A.; O’Neill, R.D.; Lowry, J.P. In vivo characterisation of a Nafion ${ }^{\circledR}$-modified Pt electrode for real-time nitric oxide monitoring in brain extracellular fluid. Anal. Methods 2012, 4, 550-557.

20. Finnerty, N.J.; O’Riordan, S.L.; Palsson, E.; Lowry, J.P. Brain nitric oxide: Regional characterisation of a real-time microelectrochemical sensor. J. Neurosci. Methods 2012, 209, 13-21.

21. Wynne, A.M.; Reid, C.H.; Finnerty, N.J. In vitro characterisation of ortho phenylenediamine and Nafion ${ }^{\circledR}$-modified pt electrodes for measuring brain nitric oxide. J. Electroanal. Chem. 2014, 732, 110-116.

22. Bolger, F.B.; Bennett, R.; Lowry, J.P. An in vitro characterisation comparing carbon paste and Pt microelectrodes for real-time detection of brain tissue oxygen. Analyst 2011, 136, 4028-4035.

23. Serra, P.A.; Hebel, M.; Rocchitta, G.; Tate, R.F. Biotelemetry NET for Neurochemical Biosensor and Microsensor Applications: Design, Construction and Validation; Nova Science Publishers, Inc.: Hauppauge, NY, USA, 2009; pp. 119-144.

24. Zhai, W.; Tian, X.; Yan, Y.; Xu, Y.; Zhao, Y.; Liu, Y. Preparation and characterization of a poly-o-phenylenediamine film modified glassy carbon electrode as a $\mathrm{H}_{2} \mathrm{O}_{2}$ sensor. Can. J. Chem. Revue Can. Chim. 2013, 91, 1077-1084. 
25. O’Brien, K.B.; Killoran, S.J.; O’Neill, R.D.; Lowry, J.P. Development and characterization in vitro of a catalase-based biosensor for hydrogen peroxide monitoring. Biosens. Bioelectron. 2007, 22, 2994-3000.

26. Rothwell, S.A.; Killoran, S.J.; O’Neill, R.D. Enzyme immobilization strategies and electropolymerization conditions to control sensitivity and selectivity parameters of a polymer-enzyme composite glucose biosensor. Sensors 2010, 10, 6439-6462.

27. Rothwell, S.A.; O’Neill, R.D. Effects of applied potential on the mass of non-conducting poly(ortho-phenylenediamine) electro-deposited on eqcm electrodes: Comparison with biosensor selectivity parameters. Phys. Chem. Chem. Phys. 2011, 13, 5413-5421.

28. Killoran, S.J.; O’Neill, R.D. Characterization of permselective coatings electrosynthesized on Pt-Ir from the three phenylenediamine isomers for biosensor applications. Electrochim. Acta 2008, 53, 7303-7312.

29. Kirwan, S.M.; Rocchitta, G.; McMahon, C.P.; Craig, J.D.; Killoran, S.J.; O’Brien, K.B.; Serra, P.A.; Lowry, J.P.; O’Neill, R.D. Modifications of poly(o-phenylenediamine) permselective layer on Pt-Ir for biosensor application in neurochemical monitoring. Sensors 2007, 7, 420-437.

30. Lowry, J.P.; O’Neill, R.D. Partial characterisation of in vitro glucose oxidase-modified poly(phenylenediamine)-coated electrodes for neurochemical analysis in vivo. Electroanalysis 1994, 6, 369-379.

31. Geise, R.J.; Adams, J.M.; Barone, N.J.; Yacynych, A.M. Electropolymerized films to prevent interferences and electrode fouling in biosensors. Biosens. Bioelectron. 1991, 6, 151-160.

32. Hashemi, P.; Dankoski, E.C.; Petrovic, J.; Keithley, R.B.; Wightman, R.M. Voltammetric detection of 5-hydroxytryptamine release in the rat brain. Anal. Chem. 2009, 81, 9462-9471.

33. Chou, J.; Ilgen, T.J.; Gordon, S.; Ranasinghe, A.D.; McFarland, E.W.; Metiu, H.; Buratto, S.K. Investigation of the enhanced signals from cations and dopamine in electrochemical sensors coated with Nafion. J. Electroanal. Chem. 2009, 632, 97-101.

34. Crespi, F.; Mobius, C. In vivo selective monitoring of basal levels of cerebral dopamine using voltammetry with Nafion modified (NA-CRO) carbon fiber microelectrodes. J. Neurosci. Methods 1992, 42, 149-161.

35. Brazell, M.P.; Kasser, R.J.; Renner, K.J.; Feng, J.; Moghaddam, B.; Adams, R.N. Electrocoating carbon-fiber microelectrodes with Nafion improves selectivity for electroactive neurotransmitters. J. Neurosci. Methods 1987, 22, 167-172.

36. Zook, L.A.; Leddy, J. Density and solubility of Nafion: Recast, annealed, and commercial films. Anal. Chem. 1996, 68, 3793-3796.

37. Fan, Z.H.; Harrison, D.J. Permeability of glucose and other neutral species through recast perfluorosulfonated ionmer films. Anal. Chem. 1992, 64, 1304-1311.

38. Mercado, R.C.; Moussy, F. In vitro and in vivo mineralization of Nafion membrane used for implantable glucose sensors. Biosens. Bioelectron. 1998, 13, 133-145.

39. Barbosa, R.M.; Lourenco, C.F.; Santos, R.M.; Pomerleau, F.; Huettl, P.; Gerhardt, G.A.; Laranjinha, J. In vivo real-time measurement of nitric oxide in anesthetized rat brain. In Nitric Oxide, Part G: Oxidative and Nitrosative Stress in Redox Regulation of Cell Signaling; Cadenas, E., Packer, L., Eds.; Elsevier Academic Press Inc.: San Diego, CA, USA. 2008; Volume 441, pp. 351-367. 
40. Craig, J.D.; O’Neill, R.D. Comparison of simple aromatic amines for electrosynthesis of permselective polymers in biosensor fabrication. Analyst 2003, 128, 905-911.

41. McMahon, C.P.; Rocchitta, G.; Serra, P.A.; Kirwan, S.M.; Lowry, J.P.; O’Neill, R.D. Control of the oxygen dependence of an implantable polymer/enzyme composite biosensor for glutamate. Anal. Chem. 2006, 78, 2352-2359.

42. Rice, M.E.; Nicholson, C. Measurement of nanomolar dopamine diffusion using low-noise perfluorinated ionomer coated carbon-fiber microelectrodes and high-speed cyclic voltammetry. Anal. Chem. 1989, 61, 1805-1810.

43. Perez, S.; Bartroli, J.; Fabregas, E. Amperometric biosensor for the determination of histamine in fish samples. Food Chem. 2013, 141, 4066-4072.

44. Arslan, F.; Ustabas, S.; Arslan, H. An amperometric biosensor for glucose determination prepared from glucose oxidase immobilized in polyaniline-polyvinylsulfonate film. Sensors $\mathbf{2 0 1 1}$, $11,8152-8163$.

45. Gyurcsanyi, R.E.; Cristalli, A.; Nagy, G.; Nagy, L.; Corder, C.; Pendley, B.D.; Ufer, S.; Nagle, H.T.; Neuman, M.R.; Lindner, E. Analytical perfomance characteristics of thin and thick film amperometric microcells. Fresnius J. Anal. Chem. 2001, 369, 286-294.

46. Sasso, S.V.; Pierce, R.J.; Walla, R.; Yacynych, A.M. Electropolymerized 1,2-diaminobenzene as a means to prevent interferences and fouling and to stabilize immobilized enzyme in electrochemical biosensors. Anal. Chem. 1990, 62, 1111-1117.

(C) 2015 by the authors; licensee MDPI, Basel, Switzerland. This article is an open access article distributed under the terms and conditions of the Creative Commons Attribution license (http://creativecommons.org/licenses/by/4.0/). 